\title{
Characterization of Severe Arterial Phase Respiratory Motion Artifact on Gadoxetate Disodium-Enhanced MRI - Assessment of Interrater Agreement and Reliability
}

\author{
Charakterisierung transienter atemabhängiger Artefakte in \\ der Leber-MRT mit Gd-EOB-DTPA als Voraussetzung für \\ Multizenterstudien - Wie einig sind sich Radiologen?
}

Authors

Kristina Imeen Ringe ${ }^{1}$, Julian A. Luetkens ${ }^{2}$, Rolf Fimmers ${ }^{3}$, Renate Maria Hammerstingl ${ }^{4}$, Günter Layer ${ }^{5}$, Martin H. Maurer ${ }^{6}$, Claas Philip Nähle ${ }^{7}$, Sabine Michalik ${ }^{8}$, Peter Reimer ${ }^{9}$, Christina Schraml ${ }^{10}$, Andreas G. Schreyer ${ }^{11}$, Patrick Stumpp ${ }^{12}$, Thomas J. Vogl ${ }^{4}$, Frank K. Wacker ${ }^{1}$, Winfried Willinek ${ }^{13}$, Guido Mattias Kukuk ${ }^{2}$

Affiliations

1 Department of Diagnostic and Interventional Radiology, Hannover Medical School, Hannover, Germany

2 Department of Radiology, University of Bonn, Germany

3 Department of Medical Biometry, Informatics and Epidemiology, University of Bonn, Germany

4 Department of Diagnostic and Interventional Radiology, Clinic of the Goethe University, Frankfurt, Germany

5 Department of Diagnostic and Interventional Radiology, Ludwigshafen Hospital, Hannover, Germany

6 Department of Radiology, University Hospital Bern, Switzerland

7 Division of Radiology and Nuclear Medicine, Cantonal Hospital St. Gallen, Switzerland

8 Department of Radiology, Asklepios Hospital Altona, Hamburg, Germany

9 Institute of Diagnostic and Interventional Radiology, Hospital Karlsruhe, Germany

10 Department of Diagnostic and Interventional Radiology, University Hospital of Tübingen, Germany

11 Department of Radiology, University Hospital Regensburg, Germany

12 Department of Radiology, University Hospital Leipzig, Germany

13 Department of Radiology, Hospital of Barmherzige Brüder, Trier, Germany

Key words

gadoxetate disodium, Gd-EOB-DTPA, motion artifact, respiratory, interrater agreement, interrater reliability

received 15.06.2017

accepted 19.12.2017
Bibliography

DOI https://doi.org/10.1055/s-0044-100727

Published online: 15.2.2018

Fortschr Röntgenstr 2018; 190: 341-347

(c) Georg Thieme Verlag KG, Stuttgart · New York

ISSN 1438-9029

Correspondence

Dr. Kristina Imeen Ringe

Institut für Diagnostische und Interventionelle Radiologie, Medizinische Hochschule Hannover, Carl-Neuberg Strasse 1, 30625 Hannover, Germany

Tel.: ++49/5 11/5323424

Fax: ++49/511/5323885

ringe.kristina@mh-hannover.de

\section{ZUSAMMENFASSUNG}

Ziel Evaluation der Interreader-Übereinstimmung und -Reliabilität zwischen erfahrenen Radiologen im Hinblick auf die Beurteilung und Graduierung atemabhängiger Artefakte in der Leber-MRT mit Gd-EOB-DTPA.

Material und Methoden In dieser prospektiven Multizenterstudie (initiiert durch die AG Gastrointestinal- und Abdominaldiagnostik der DRG) wurden Gd-EOB-DTPA verstärkte MRT-Untersuchungen von 40 Patienten (25 Männer, 15 Frauen; mittleres Alter 59 Jahre) durch 11 erfahrene Radiologen/innen aus Deutschland und der Schweiz ausgewertet. Evaluiert wurden das Auftreten und der Schweregrad atemabhängiger Artefakte in der arteriellen Phase der KM-Dynamik anhand eines 5-Punkte Scores. Zur Beurteilung von Übereinstimmung und Reliabilität des Scorings zwischen den Radiologen wurden der Intraklassen-Korrelationskoeffizient (ICC) und der Kendall Konkordanzkoeffizient (W) berechnet.

Ergebnisse Die Übereinstimmung zwischen den Radiologen bezüglich der Graduierung des Schweregrads des Artefakts war mit einem ICC von 0,933 (95\% Konfidenzintervall 0,973-0,990; $p<0,0001$ ) bzw. einem Kendall W von 0,865 sehr gut. Die Reliabilität bzgl. der Unterscheidung verschie- 
dener Schweregrade war zwischen den Radiologen ebenfalls sehr gut mit einem ICC von 0,985 (95\% Konfidenzintervall $0,978-0,991 ; p<0,0001)$. Schwere atemabhängige Artefakte (definiert als ein Score $\geq 4$ ) wurden in 12 Untersuchungen beobachtet. In diesen Fällen wurde in $75 \%$ (9/12) von allen Radiologen ein Score $\geq 4$ vergeben.

Schlussfolgerung Die Differenzierung und Charakterisierung atemabhängiger Artefakte in der arteriellen Phase der MRT mit Gd-EOB-DTPA durch verschiedene Radiologen ist mit hoher Übereinstimmung und Reliabilität möglich. Die zuverlässige und übereinstimmende Bewertung von Artefakten durch unterschiedliche Radiologen ist eine unabdingbare Voraussetzung für die Durchführung großer Multizenterstudien. Die Ergebnisse dieser Arbeit schaffen hierfür die Grundlage.

\section{Kernaussagen:}

- Die Inter- und Intraraterübereinstimmung für die Beurteilung atemabhängiger Artefakte ist sehr gut.

- Die Interrater Reliabilität unter erfahrenen Radiologen bezüglich der Graduierung von atemabhängigen Artefakten ist sehr gut.

- Die Charakterisierung schwerer atemabhängiger Artefakte erwies sich in dieser Multizenterstudie als zuversichtlich möglich.

\section{ABSTRACT}

Purpose To assess the interrater agreement and reliability of experienced abdominal radiologists in the characterization and grading of arterial phase gadoxetate disodium-related respiratory motion artifact on liver MRI.

Materials and Methods This prospective multicenter study was initiated by the working group for abdominal imaging within the German Roentgen Society (DRG), and approved by the local IRB of each participating center. 11 board-certi- fied radiologists independently reviewed 40 gadoxetate disodium-enhanced liver MRI datasets. Motion artifacts in the arterial phase were assessed on a 5-point scale. Interrater agreement and reliability were calculated using the intraclass correlation coefficient (ICC) and Kendall coefficient of concordance $(W)$, with $p<0.05$ deemed significant.

Results The ICC for interrater agreement and reliability were $0.983(\mathrm{Cl} 0.973-0.990)$ and 0.985 (Cl $0.978-0.991)$, respectively (both $p<0.0001$ ), indicating excellent agreement and reliability. Kendall's W for interrater agreement was 0.865 . A severe motion artifact, defined as a mean motion score $\geq 4$ in the arterial phase was observed in 12 patients. In these specific cases, a motion score $\geq 4$ was assigned by all readers in $75 \%$ ( $n=9 / 12$ cases).

Conclusion Differentiation and grading of arterial phase respiratory motion artifact is possible with a high level of inter-/intrarater agreement and interrater reliability, which is crucial for assessing the incidence of this phenomenon in larger multicenter studies.

\section{Key Points}

- Inter- and intrarater agreement for motion artifact scoring is excellent among experienced readers.

- Interrater reliability for motion artifact scoring is excellent among experienced readers.

- Characterization of severe motion artifacts proved feasible in this multicenter study.

\section{Citation Format}

- Ringe KI, Luetkens JA, Fimmers R et al. Characterization of Severe Arterial Phase Respiratory Motion Artifact on Gadoxetate Disodium-Enhanced MRI - Assessment of Interrater Agreement and Reliability. Fortschr Röntgenstr 2018; 190: 341-347

\section{Introduction}

Gadoxetate disodium (Gd-EOB-DTPA, Primovist, Eovist, Bayer Healthcare) is a liver specific contrast agent, demonstrating an uptake by hepatocytes and subsequent biliary excretion of approximately $50 \%$ in patients with normal liver and kidney function [1]. Based on the specific pharmacodynamic and pharmacokinetic properties, the use of this contrast agent results in improved detection and characterization of focal liver lesions not only in the non-cirrhotic but also in the cirrhotic liver. In this context, proper arterial phase imaging is crucial, especially for lesion characterization.

Recently, an association has been described between the intravenous injection of gadoxetate disodium and motion artifacts in the arterial phase of the contrast dynamic, which has been termed acute transient severe motion (TSM) [2, 3]. This phenomenon is typically self-limiting, lasts for about 10 to 20 seconds and may be accompanied by a subjective feeling of transient dyspnea [4]. TSM-induced artifacts may have destructive effects on arterial phase MRI image quality, resulting in non-diagnostic images in the worst case. The exact pathophysiology of this unaccounted for phenomenon is still unknown, and several patient-related as well as MR-specific risk factors are being discussed [5]. More importantly, the reported incidence of TSM throughout the literature is not consistent, covering a wide range from $2.4 \%$ up to $18 \%[3,6]$.

One possible explanation for this discrepancy might be the difficulty of differentiating motion artifacts from other sources of image degradation, such as truncation artifacts [7]. To the best of our knowledge, there is no prior study in the literature specifically addressing the matter of interrater agreement and reliability in this context. In order to reliably evaluate respiratory motion artifacts and TSM in larger studies comprising multiple institutions with multiple readers, artifact scoring must be consistent and robust.

To address this problem, the working group for abdominal imaging within the German Roentgen Society (AG Gastrointestinal- und Abdominaldiagnostik, Deutsche Röntgengesellschaft) initiated a multicenter study in which MRI examinations of more than 2000 patients are being evaluated. As a prerequisite, the 
purpose of this study is to assess interrater agreement and reliability among expert abdominal radiologists with respect to the grading of arterial phase respiratory motion artifacts in gadoxetate disodium-enhanced MRI by means of a 5-point score. The null hypothesis was that there is no significant difference between multiple readers regarding the scoring of severe arterial phase respiratory motion artifacts.

\section{Materials and Methods}

This multicenter study was approved by the local institutional review board (IRB) of each participating center, with a waiver of informed patient consent granted for the prospective analysis of retrospective data. Our pilot study was conducted in order to test the robustness of a scoring system intended to be used in a large European multicenter study, assessing the incidence and underlying risk factors of TSM on gadoxetate disodium-enhanced MRI.

\section{Selection and preparation of datasets}

Two radiologists of the coordinating study center selected 40 gadoxetate disodium-enhanced liver MRI datasets from 40 different patients ( 25 male, 15 female; mean age: $59.4 \pm 15.9$ years). The datasets were chosen to include examinations without as well as with respiratory motion artifacts of varying severity. A single axial image in the arterial phase, encompassing the upper abdomen at the level of the suprarenal aorta was generated from each dataset. Images were merged in random order into a single file for further reading. In addition, an exemplary set of images (not including the study datasets) demonstrating motion artifacts of varying degrees was presented to the readers. All images were acquired on a 1.5 T scanner using the bolus detection technique and standard dosing of $0.025 \mathrm{mmol} / \mathrm{kg}$ gadoxetate disodium injected at a flow rate of $1.5 \mathrm{ml} / \mathrm{sec}$, followed by a saline flush of $25 \mathrm{ml}$.

\section{Characterization of readers}

11 radiologists from 11 different institutions from Germany and Switzerland participated in this trial. All readers were board-certified radiologists with substantial experience in abdominal MR imaging, in order to ensure homogeneity of our study findings. Readers were at least 5 years post board certification and had a minimum of 8 years of experience regarding the interpretation of abdominal MRI. Notably, every reader had knowledge of the appearance of respiratory motion artifacts and differentiation from other sources of image degradation, such as truncation. To preserve anonymity, the order of the readers' appearance in the figures and tables is neither consistent throughout the manuscript nor is it consistent with the authorship order.

\section{Image evaluation}

All readers independently assessed the prepared image datasets with regard to respiratory motion-related artifacts using a 5-point scale. If other artifacts were observed (e. g. truncation, pulsation), readers were asked to ignore these. Score 1: no motion-related artifact; Score 2: minimal motion-related artifact with no effect on diagnostic quality; Score 3: moderate motion-related artifact with some, but not severe effect on diagnostic quality; Score 4: severe motion-related artifact, but images are still interpretable; Score 5: extensive motion-related artifact resulting in non-diagnostic image quality ( $\triangleright$ Fig. 1). This scoring system has been used in previous studies [2, 8], but to our knowledge has not yet been validated in a large multicenter and multireader setting. All radiologists were blinded to the ratings of the other radiologists. In addition, four readers performed a second assessment of all datasets in order to evaluate intrarater agreement. The interval between both reading sessions was longer than two months in order to avoid any recall bias.

\section{Statistical analysis}

Statistical analysis was performed using SPSS software (version 22; SPSS; Chicago, Illinois). Interrater agreement was defined as the extent to which different readers assigned the same precise motion score on MRI datasets. The general trend in ratings was addressed by means of interrater reliability, assessing the extent to which readers could consistently distinguish between different motion scores [9]. For validation of interrater agreement and interrater reliability, the intraclass correlation coefficient (ICC) was calculated according to McGraw and Wong [10], applying a two-way mixed model. In addition, the Kendall coefficient of concordance (W) for further evaluation of the interrater agreement was calculated. The intrarater agreement was calculated similarly. The ICC and Kendall W were interpreted as follows: a value less than 0.20 indicated poor agreement; a value of $0.21-0.40$ fair agreement; a value of $0.41-0.60$ moderate agreement; a value of $0.61-0.80$ substantial agreement; and a value of $0.81-1.00$ almost perfect agreement [11]. For all measurements, $p<0.05$ indicated a significant difference.

\section{Results}

\section{Scoring of motion artifacts}

All readers assigned motion scores ranging from 1 to 5 . The median motion score assigned by the readers averaged over all 40 datasets was either 2 or 3 . Only in one case $(2.5 \%)$ with extensive motion artifacts and non-diagnostic image quality (score 5), all readers assigned the same motion score. In 6 cases (15\%), 10 out of 11 readers assigned the same motion score. Clinically irrelevant motion artifacts, defined as a mean motion score $\leq 3$ on arterial phase images, were observed in 28 patients. Among these cases, motion artifacts were rated with a score $\leq 3$ by all readers in $79 \%$ of cases ( $n=22$ out of 28 cases). Severe or extensive motion artifacts, defined as a mean motion score $\geq 4$ in the arterial phase, were observed in 12 patients. In these specific cases, a motion score $\geq 4$ was assigned by all readers in $75 \%$ of cases ( $n=9$ out of 12 cases) ( $\triangleright$ Table $\mathbf{1}, \triangleright$ Fig. 2 ).

\section{Interrater agreement and reliability}

The interrater agreement, defined as the extent to which different readers assigned the same precise motion score and as assessed 

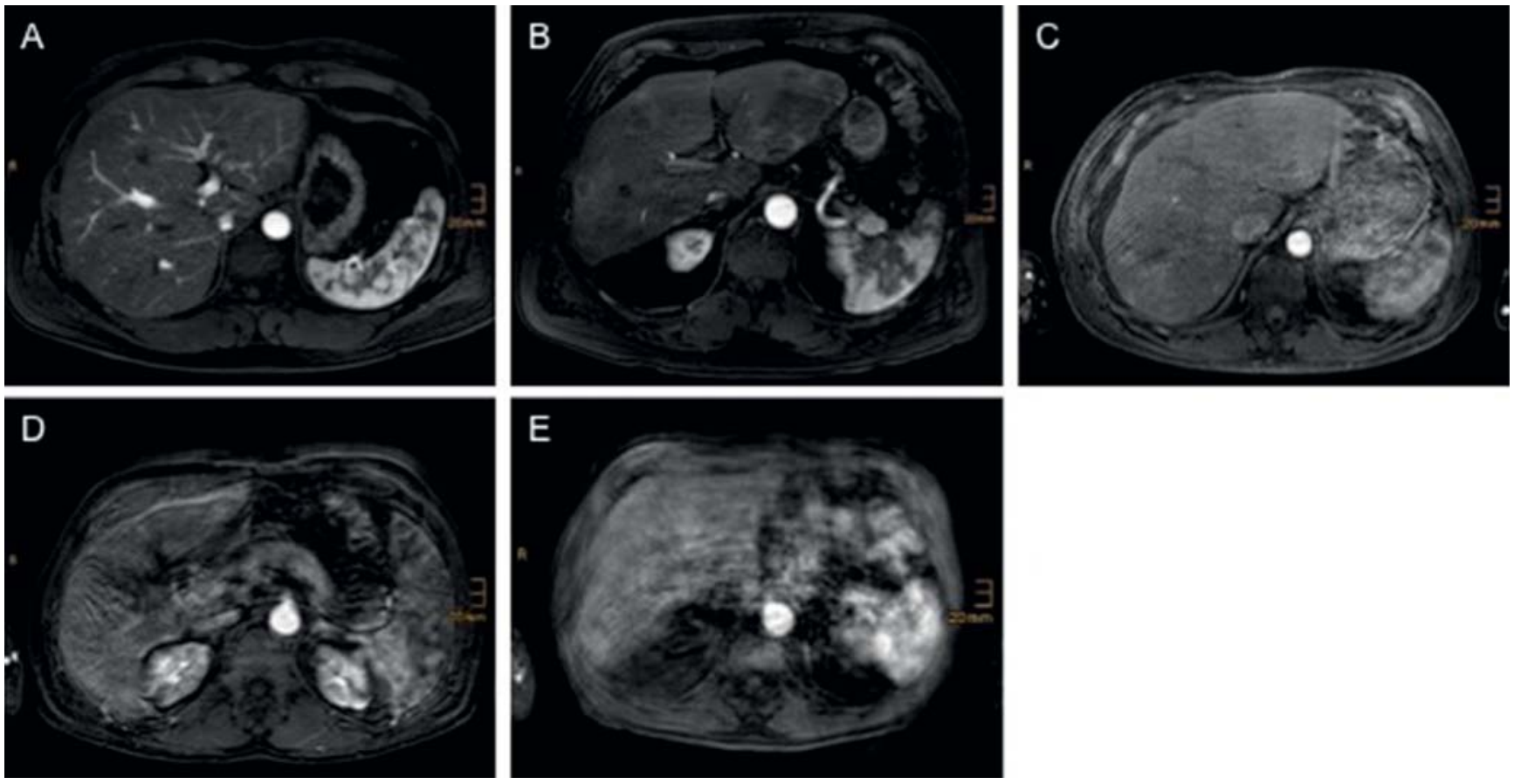

- Fig. 1 Demonstration of motion-related artifacts in the arterial phase on gadoxetate disodium-enhanced. MRI Motion-related artifacts were evaluated by means of a 5-point scale. Score 1: no motion-related artifact A; Score 2: minimal motion-related artifact with no effect on diagnostic quality B; Score 3: moderate motion-related artifact with some, but not severe effect on diagnostic quality C; Score 4: severe motion-related artifact, but images are still interpretable $\mathbf{D}$; Score 5: extensive motion-related artifact resulting in non-diagnostic image quality $\mathbf{E}$.

- Abb. 1 Atemabhängige Artefakte in der arteriellen Phase der MRT mit Gd-EOB-DTPA. Graduierung atemabhängiger Artefakte anhand einer 5-Punkte Skala. 1: keine atemabhängigen Artefakte A; 2: minimale atemabhängige Artefakte, keine Beeinträchtigung der diagnostischen Bildqualität B; 3: mäßige atemabhängige Artefakte, keine starke Beeinträchtigung der diagnostischen Bildqualität C; 4 : deutliche atemabhängige Artefakte, Bilder noch beurteilbar D; 5: schwere atemabhängige Artefakte, nicht-diagnostische Bildqualität $\mathbf{E}$.

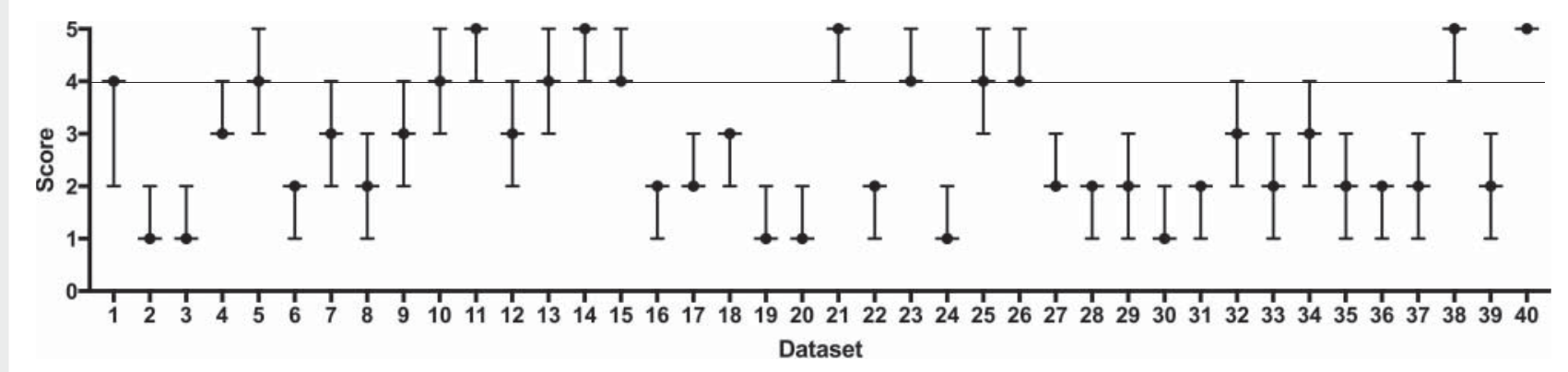

- Fig. 2 Scoring of motion artifact as assessed by 11 radiologists on a 5-point scale. Presented are mean values and the range of motion scores separately for all 40 datasets. The horizontal line indicates the cut-off $(\geq 4)$ that makes an artifact severe.

- Abb.2 Graduierung atemabhängiger Artefakte durch 11 Radiologen anhand einer 5-Punkte Skala. Darstellung der Mittelwerte und Spannweite der Ergebnisse separat für 40 Datensätze. Die horizontale Linie stellt den cut-off Wert dar ( $\geq 4)$, ab wann ein Artefakt als schwerwiegend gewertet wird.

by means of the ICC, was 0.983 (95\% confidence intervals 0.973 $0.990 ; p<0.0001)$. The Kendall $W$ for assessment of interrater agreement was $0.865(p<0.0001)$. Both values indicated almost perfect interrater agreement regarding the rating of the motion artifact on arterial phase gadoxetate disodium-enhanced MRI. The interrater reliability, assessing the extent to which readers could consistently distinguish between different motion scores, was very high as well with an ICC of 0.985 (95\% confidence inter- vals $0.978-0.991 ; p<0.0001)$. Image examples are presented in - Fig. 3.

\section{Intrarater agreement}

The intrarater agreement among all four radiologists was almost perfect, with a mean ICC of 0.935 (range: $0.886-0.980$ ) and a mean $95 \%$ confidence interval of $0.873-0.966$ (range: 0.781 - 
- Table 1 Rating results of motion artifacts on gadoxetate disodium-enhanced arterial phase MRI, as assessed individually by 11 radiologists (R01 11) on a 5-point scale. In addition, the median motion score of each reader is provided, as well as the median motion score for each dataset including the percentage agreement for that specific score $(\% \mathrm{Ag})$. Data is sorted according to the median.

- Tab. 1 Graduierung von Atemartefakten durch 11 Radiologen (R01 - 11) anhand einer 5-Punkte Skala. Zusätzlich Angabe des Median-Scores und der Übereinstimmung in Hinblick auf diesen (\%Ag). Die Daten sind entsprechend des Median-Scores sortiert.

\begin{tabular}{|c|c|c|c|c|c|c|c|c|c|c|c|c|c|}
\hline dataset & R01 & R02 & R03 & R04 & R05 & R06 & R07 & R08 & R09 & R10 & R11 & median & $\% \mathbf{A g}$ \\
\hline 40 & 5 & 5 & 5 & 5 & 5 & 5 & 5 & 5 & 5 & 5 & 5 & 5 & 100 \\
\hline 14 & 5 & 5 & 4 & 4 & 5 & 5 & 5 & 5 & 5 & 5 & 5 & 5 & 81.8 \\
\hline 21 & 4 & 5 & 5 & 4 & 4 & 4 & 5 & 5 & 5 & 5 & 5 & 5 & 63.6 \\
\hline 11 & 4 & 5 & 4 & 4 & 4 & 5 & 4 & 5 & 5 & 5 & 5 & 5 & 54.5 \\
\hline 38 & 5 & 5 & 4 & 4 & 4 & 4 & 5 & 4 & 5 & 5 & 5 & 5 & 54.5 \\
\hline 15 & 4 & 4 & 4 & 4 & 4 & 4 & 4 & 4 & 4 & 5 & 4 & 4 & 90.9 \\
\hline 26 & 4 & 4 & 4 & 4 & 4 & 4 & 4 & 4 & 4 & 4 & 5 & 4 & 90.9 \\
\hline 10 & 3 & 4 & 4 & 4 & 4 & 4 & 4 & 4 & 4 & 5 & 5 & 4 & 72.7 \\
\hline 23 & 4 & 5 & 4 & 4 & 4 & 5 & 4 & 4 & 5 & 4 & 4 & 4 & 72.7 \\
\hline 1 & 3 & 4 & 4 & 3 & 2 & 4 & 4 & 4 & 3 & 4 & 4 & 4 & 63.6 \\
\hline 13 & 4 & 4 & 4 & 3 & 3 & 4 & 5 & 4 & 4 & 5 & 4 & 4 & 63.6 \\
\hline 5 & 4 & 4 & 3 & 4 & 4 & 4 & 4 & 3 & 3 & 5 & 3 & 4 & 54.5 \\
\hline 4 & 3 & 4 & 3 & 3 & 3 & 3 & 3 & 3 & 3 & 4 & 3 & 3 & 81.8 \\
\hline 18 & 3 & 3 & 2 & 3 & 2 & 2 & 3 & 3 & 3 & 3 & 3 & 3 & 72.7 \\
\hline 12 & 3 & 3 & 2 & 3 & 2 & 2 & 3 & 3 & 3 & 3 & 4 & 3 & 63.6 \\
\hline 25 & 3 & 4 & 3 & 3 & 3 & 4 & 5 & 3 & 3 & 3 & 4 & 3 & 63.6 \\
\hline 9 & 3 & 2 & 3 & 3 & 2 & 4 & 3 & 2 & 3 & 3 & 4 & 3 & 54.5 \\
\hline 32 & 2 & 3 & 2 & 2 & 2 & 3 & 3 & 2 & 3 & 3 & 4 & 3 & 45.5 \\
\hline 34 & 2 & 3 & 3 & 3 & 2 & 2 & 3 & 2 & 3 & 2 & 4 & 3 & 45.5 \\
\hline 27 & 2 & 3 & 2 & 2 & 2 & 2 & 2 & 2 & 2 & 2 & 2 & 2 & 90.9 \\
\hline 31 & 2 & 2 & 2 & 2 & 2 & 2 & 2 & 1 & 2 & 2 & 2 & 2 & 90.9 \\
\hline 17 & 2 & 3 & 2 & 2 & 2 & 3 & 2 & 2 & 2 & 2 & 2 & 2 & 81.8 \\
\hline 35 & 2 & 2 & 1 & 2 & 2 & 2 & 2 & 2 & 2 & 2 & 3 & 2 & 81.8 \\
\hline 39 & 2 & 3 & 1 & 2 & 2 & 2 & 2 & 2 & 2 & 2 & 2 & 2 & 81.8 \\
\hline 16 & 2 & 2 & 1 & 2 & 2 & 2 & 2 & 2 & 2 & 1 & 1 & 2 & 72.2 \\
\hline 6 & 2 & 2 & 1 & 1 & 2 & 2 & 2 & 2 & 1 & 1 & 2 & 2 & 63.6 \\
\hline 7 & 2 & 3 & 2 & 2 & 2 & 3 & 4 & 2 & 3 & 2 & 2 & 2 & 63.6 \\
\hline 29 & 2 & 2 & 2 & 1 & 2 & 2 & 2 & 3 & 2 & 3 & 3 & 2 & 63.6 \\
\hline 33 & 2 & 2 & 2 & 3 & 2 & 1 & 2 & 2 & 3 & 2 & 3 & 2 & 63.6 \\
\hline 8 & 2 & 2 & 2 & 3 & 2 & 3 & 3 & 1 & 2 & 2 & 3 & 2 & 54.5 \\
\hline 22 & 1 & 2 & 1 & 1 & 2 & 1 & 2 & 1 & 2 & 2 & 2 & 2 & 54.5 \\
\hline 36 & 1 & 2 & 1 & 1 & 1 & 2 & 1 & 2 & 2 & 2 & 2 & 2 & 54.5 \\
\hline 37 & 2 & 3 & 2 & 1 & 1 & 3 & 2 & 1 & 1 & 2 & 3 & 2 & 36.4 \\
\hline 2 & 1 & 2 & 1 & 1 & 1 & 1 & 1 & 1 & 1 & 1 & 1 & 1 & 90.9 \\
\hline 3 & 1 & 1 & 1 & 1 & 1 & 1 & 1 & 2 & 1 & 1 & 1 & 1 & 90.9 \\
\hline 30 & 1 & 1 & 1 & 2 & 1 & 1 & 1 & 2 & 1 & 1 & 1 & 1 & 81.8 \\
\hline 24 & 1 & 1 & 1 & 1 & 1 & 1 & 2 & 2 & 1 & 1 & 2 & 1 & 72.7 \\
\hline 20 & 1 & 2 & 1 & 1 & 1 & 1 & 1 & 1 & 2 & 2 & 2 & 1 & 63.6 \\
\hline 19 & 1 & 2 & 1 & 2 & 1 & 1 & 1 & 2 & 2 & 1 & 2 & 1 & 54.5 \\
\hline 28 & 1 & 2 & 1 & 2 & 1 & 1 & 2 & 1 & 2 & 2 & 1 & 1 & 54.5 \\
\hline median & 2 & 3 & 2 & 3 & 2 & 3 & 3 & 2 & 3 & 2 & 3 & & \\
\hline
\end{tabular}



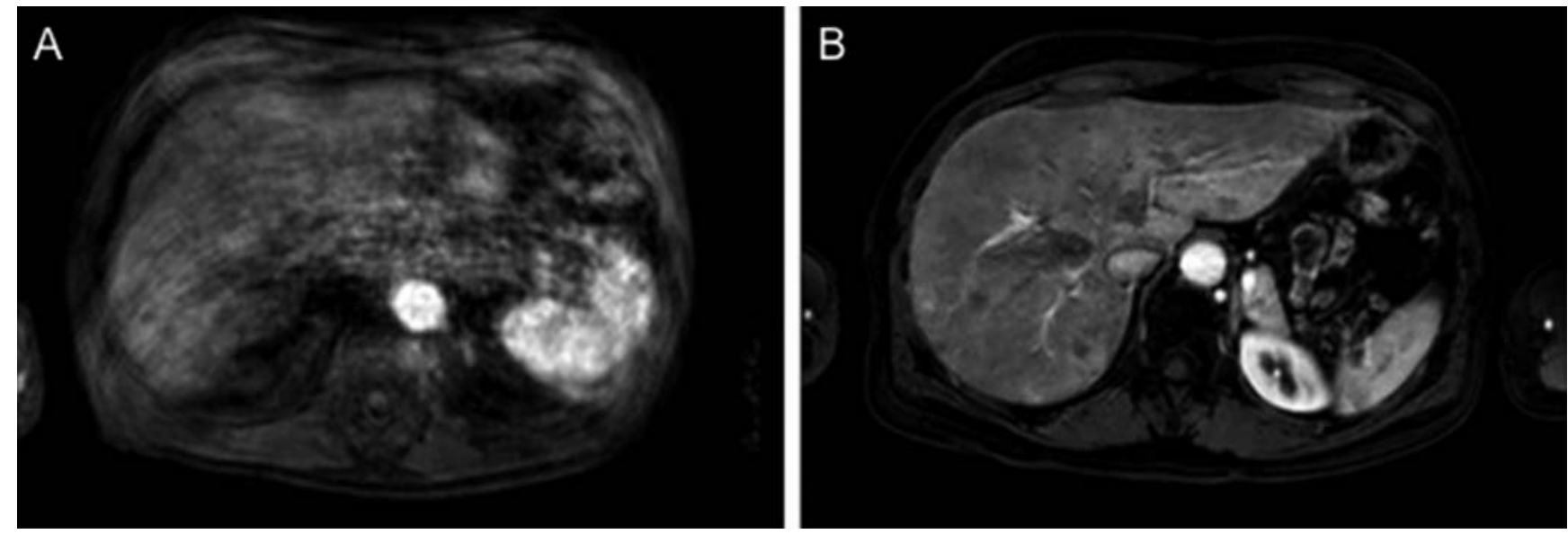

Fig. 3 Image examples of different degrees and scoring of respiratory motion artifacts. A: Case of extensive motion-related artifact (dataset \#40) that was scored by all readers with " 5 ", indicating perfect agreement and no variability. B: Case (dataset \#37) in which readers assigned scores between " 1 " and " 3 ", demonstrating higher variability and less agreement.

- Abb.3 Bildbeispiele unterschiedlicher Artefaktausprägungen und entsprechender Bewertungen. A: Schwere atemabhängige Artefakte. Der Datensatz (\#40) wurde von allen Radiologen mit „5“ bewertet, entsprechend einer perfekten Übereinstimmung und fehlenden Variabilität. B: Datensatz \#37, der von den einzelnen Radiologen unterschiedlich mit „1“ bis „3“ Punkten bewertet wurde. Entsprechend ist die Variabilität höher und die Übereinstimmung der Bewertungen niedriger.

0.989; $p<0.0001$ for all readers). Similarly, Kendall W for assessment of intrarater agreement was very good with a mean of 0.935 (range: $0.912-0.975 ; \mathrm{p} \leq 0.001$ for all readers).

\section{Discussion}

In this multicenter study, we observed high interrater agreement and reliability for the assessment of TSM on arterial phase gadoxetate disodium-enhanced MRI. Results were substantiated by an almost perfect intrarater agreement, which has, to the best of our knowledge, not been specifically evaluated in the context of arterial phase motion artifacts. Due to the possible detrimental effects of respiratory motion on dynamic liver MRI, robust characterization and scoring in large multicenter studies is essential for the evaluation of this unaccounted for phenomenon. It needs to be emphasized that we assessed interrater agreement and reliability separately, two terms that are often incorrectly used interchangeably throughout the literature. While agreement is defined as the degree to which ratings given by different judges (here: assigned motion artifact scores by different readers) are identical, reliability refers to the consistency of ratings and the extent of variability [9]. Our findings could thus contribute to better interpretation and understanding of motion artifact scoring in multireader and multicenter studies.

The scoring system for the assessment of motion artifacts used in our study has been described in previous smaller studies with two to five readers only, with a high interrater agreement and reliability. Davenport et al. reported good agreement for the scoring of motion in the arterial phase between two readers with an ICC of 0.90 [12]. Kim et al. presented comparable results in a two reader setting with an ICC ranging from 0.87 to 0.97 for different phases of the contrast dynamic [13]. In the initial study conducted by Davenport and colleagues, excellent reliability among 5 read- ers for the scoring of motion was reported with an ICC between 0.85 and 0.95 for different contrast phases. Results regarding interrater or intrarater agreement were not presented [2]. Pietryga et al. in contrast calculated interrater agreement, and not reliability, among five readers. The ICCs for motion scores ranged from moderate for the pre-contrast phases $($ ICC $=0.53$ ) to excellent for the second arterial phase $(I C C=0.90)$ [8]. The results of these previous studies are in line with those of our present study. However, in most of these earlier studies readers were from the same institution evaluating their own datasets, which constitutes a potential bias.

Looking at the motion scores in our study in detail, all readers assigned the same score only in one case. Specifically, this was a case with extensive motion artifacts and non-diagnostic image quality. Taking this into account, one could hypothesize that a non-clustered score (e.g. 1, 2, 3 instead of 1-5) could be solid enough to evaluate motion artifacts on gadoxetate disodium-enhanced MRI. On the other hand, we were able to demonstrate that the applied scoring system is solid and practical, and that high interrater agreement and reliability can be achieved in a multicenter setting if a standardized scoring system is used.

Nonetheless, our study also has limitations. First, only one phase of the contrast dynamic, namely the late arterial, was evaluated. We chose to focus on this specific phase as it is the most important phase when it comes to evaluating severe transient motion on gadoxetate disodium-enhanced MRI. On the other hand, rating of a single phase can also be considered as a strength of this study, as the reader does not have any other phases or images for comparison, which could facilitate image evaluation. Secondly, readers were asked to score motion artifacts only. Other artifacts, which may also cause image degradation, were not scored specifically. Motion artifacts need to be differentiated especially from truncation or ringing artifacts (also known as 
Gibbs's artifacts), which originate from vessels and decay with distance from the source. Motion artifacts, however, are located randomly throughout the image extending into the noise outside the body [7, 14]. One possible explanation for the discrepancy regarding the reported incidence of TSM within the literature might be the difficulty in differentiating between these types of artifacts. The results of our present study, however, show that motion artifacts may be differentiated and graded reliably if experienced radiologists perform the assessment.

In conclusion, we confirm the null hypothesis that there is no significant difference between multiple readers from different institutions regarding the assessment of severe respiratory motion artifacts. The consistency of rating, as demonstrated by our study results, may have implications for future studies, especially those in which subjective assessment of image quality and artifacts is part of the evaluation process. The results of our data will enhance the scientific value of an envisaged large European multicenter study, aiming at assessing the incidence and underlying risk factors for transient severe motion artifact on gadoxetate disodium-enhanced MRI.

\section{Conflict of Interest}

The authors declare that they have no conflict of interest.

\section{References}

[1] van Montfoort JE, Stieger B, Meijer DK et al. Hepatic uptake of the magnetic resonance imaging contrast agent gadoxetate by the organic anion transporting polypeptide Oatp1. J Pharmacol Exp Ther 1999; 290: 153 157

[2] Davenport MS, Viglianti BL, Al-Hawary MM et al. Comparison of acute transient dyspnea after intravenous administration of gadoxetate disodium and gadobenate dimeglumine: effect on arterial phase image quality. Radiology 2013; 266: $452-461$
[3] Davenport MS, Caoili EM, Kaza RK et al. Matched within-patient cohort study of transient arterial phase respiratory motion-related artifact in MR imaging of the liver: gadoxetate disodium versus gadobenate dimeglumine. Radiology 2014; 272: 123 -131

[4] Motosugi U, Bannas P, Bookwalter CA et al. An Investigation of Transient Severe Motion Related to Gadoxetic Acid-enhanced MR Imaging. Radiology 2016; 279: $93-102$

[5] Huh J, Kim SY, Yeh BM et al. Troubleshooting Arterial-Phase MR Images of Gadoxetate Disodium-Enhanced Liver. Korean J Radiol 2015; 16 : $1207-1215$

[6] Luetkens JA, Kupczyk PA, Doerner J et al. Respiratory motion artefacts in dynamic liver MRI: a comparison using gadoxetate disodium and gadobutrol. Eur Radiol 2015; 25: 3207 - 3213

[7] Huang SY, Seethamraju RT, Patel P et al. Body MR Imaging: Artifacts, k-Space, and Solutions. Radiographics 2015; 35: 1439-1460

[8] Pietryga JA, Burke LM, Marin D et al. Respiratory motion artifact affecting hepatic arterial phase imaging with gadoxetate disodium: examination recovery with a multiple arterial phase acquisition. Radiology 2014; 271 : $426-434$

[9] Gisev N, Bell JS, Chen TF. Interrater agreement and interrater reliability: key concepts, approaches, and applications. Res Social Adm Pharm 2013; 9: $330-338$

[10] McGraw KO, Wong SP. Forming interferences about some intraclass correlation coefficients. Psychol Methods 1996; 1: 30-46

[11] Landis JR, Koch GG. The measurement of observer agreement for categorical data. Biometrics 1977; 33: 159-174

[12] Davenport MS, Bashir MR, Pietryga JA et al. Dose-toxicity relationship of gadoxetate disodium and transient severe respiratory motion artifact. Am J Roentgenol 2014; 203: 796-802

[13] Kim SY, Park SH, Wu EH et al. Transient respiratory motion artifact during arterial phase MRI with gadoxetate disodium: risk factor analyses. Am J Roentgenol 2015; 204: 1220-1227

[14] Bashir MR, Castelli P, Davenport MS et al. Respiratory motion artifact affecting hepatic arterial phase MR imaging with gadoxetate disodium is more common in patients with a prior episode of arterial phase motion associated with gadoxetate disodium. Radiology 2015; 274: 141 - 148 